\title{
A Micro Aerosol Sensor for the Measurement of Airborne Ultrafine Particles
}

\author{
Chao Zhang ${ }^{1}$, Rong Zhu ${ }^{1, *}$ and Wenming Yang ${ }^{2}$ \\ 1 State Key Laboratory of Precision Measurement Technology and Instrument, Department of Precision \\ Instrument, Tsinghua University, Beijing 100084, China; zhangchao14@mails.tsinghua.edu.cn \\ 2 School of Mechanical Engineering, University of Science and Technology Beijing, Beijing 100083, China; \\ wmyang@ustb.edu.cn \\ * Correspondence: zr_gloria@mail.tsinghua.edu.cn; Tel.: +86-10-6278-8935 \\ Academic Editor: W. Rudolf Seitz \\ Received: 18 December 2015; Accepted: 16 March 2016; Published: 18 March 2016
}

\begin{abstract}
Particle number concentration and particle size are the two key parameters used to characterize exposure to airborne nanoparticles or ultrafine particles that have attracted the most attention. This paper proposes a simple micro aerosol sensor for detecting the number concentration and particle size of ultrafine particles with diameters from 50 to $253 \mathrm{~nm}$ based on electrical diffusion charging. The sensor is composed of a micro channel and a couple of planar electrodes printed on two circuit boards assembled in parallel, which thus integrate charging, precipitating and measurement elements into one chip, the overall size of which is $98 \times 38 \times 25 \mathrm{~mm}^{3}$. The experiment results demonstrate that the sensor is useful for measuring monodisperse aerosol particles with number concentrations from 300 to $2.5 \times 10^{4} / \mathrm{cm}^{3}$ and particle sizes from 50 to $253 \mathrm{~nm}$. The aerosol sensor has a simple structure and small size, which is favorable for use in handheld devices.
\end{abstract}

Keywords: ultrafine particles; number concentration; particle size; micro aerosol sensor

\section{Introduction}

Airborne nanoparticles or ultrafine particles [1,2] distributed in the atmospheric, indoor and industrial environments seriously threaten human health [3,4]. The number concentration and particle size are the two key parameters used to describe exposure to airborne nanoparticles or ultrafine particles. The toxicology research results show that aerosol particles can deposit in different parts of the human respiratory organs [4-7] according to the sizes of the particles. The particles with sizes of less than $10 \mu \mathrm{m}$ can enter the nasal cavity, those smaller than $7 \mu \mathrm{m}$ can enter the throat, and if less than $2.5 \mu \mathrm{m}$, they enter the lungs. Nanoparticles or ultrafine particles can enter into the human lungs and alveolar area, and further enter into the human blood circulation system $[8,9]$.

Measurements of the size and concentration of aerosol particles mainly involve two kinds of methods based on optical and electrical mechanisms [1]. Optical measurements require a sensor or a particle detector in the detection zone; three of the most widely used sensors are the optical particle counter (OPC) [10], the laser particle counter (LPC) [11], and the condensation particle counter (CPC) [12]. However particle size detection by light scattering loses sensitivity when the size is less than the wavelength of the light or laser used, so OPCs or LPCs can only detect particle sizes larger than $0.1 \mu \mathrm{m}$ [1]. CPCs can detect particles with sizes less than $0.1 \mu \mathrm{m}$, but to date the limitations of their compactness, portability and cost do not allow their application for personal monitoring. The particles with sizes ranging from $1 \mathrm{~nm}$ to $300 \mathrm{~nm}$ can be detected by electrical measurement. Electrical measurements can be classified into two groups, according to their specific measurement principle. One, exemplified by the Scanning Electrical Mobility Spectrometer (SEMS) [13] or Differential Mobility Analyzer (DMA) [14] techniques, is based on the fact that the electric mobility of charged particles is 
inversely proportional to the particle size. However, these instruments cannot be handheld due to their big volume and heavy weight. The other measurement methods are based on diffusion charging whereby the average charge on particles corresponds roughly with their diameter in a certain size range [1]. The aerosol particles are charged by gas ions which are ionized in a specific charger, and then excess gas ions unattached to the aerosol particles are removed so as not to affect the subsequent current measurement, and finally the number concentration and the particle size can be calculated according to the charges measured on the particles. Some handheld instruments based on the charging principle have been reported, such as the Nanomonitor [15,16], NanoCheck (Model 1.320, GSI), and Discmini [17-19] devices. The Nanomonitor can measure number concentrations of $\sim 10^{6} / \mathrm{cm}^{3}$ and averaged particle sizes between 10-300 nm, the its configuration mainly consists of three sections, i.e., charging, precipitation and sensing. It measures the charge current using a block-shaped voltage that varies between low and high voltages. At the low voltage, the excess ions are removed, while at the high voltage, a part of the charged particles are removed as well. A current meter which is connected via a Faraday cage records two different currents under low and high precipitating voltages. The particle parameters of number concentration and size can be figured out from the detected currents. The NanoCheck uses a variable ion trap voltage to obtain particle parameters which can measure particles in the size range of 25-300 nm and number concentrations of $500-5 \times 10^{5} / \mathrm{cm}^{3}$ based on the same operating principle as the Nanomonitor. The Discmini [19] can measure averaged particle sizes between $15-400 \mathrm{~nm}$ and number concentrations from 700 to $8.4 \times 10^{5} / \mathrm{cm}^{3}$. The aerosol particles are electrically charged in a corona discharger and detected in two stages. Small particles are deposited in the diffusion stage with a stack of stainless steel screens, while larger particles pass through the diffusion stage and are detected in the filter stage which contains a HEPA filter. The Nanomonitor, the NanoCheck and the Discmini all use Faraday cages, ion-traps and/or a stack of stainless steel screens to detect the charge currents which have elaborate structures, hindering further miniaturization.

Another kind of particle detector is based on a resonant cantilever [20-22]. Wasisto et al. designed an airborne nanoparticle detector based on a microelectromechanical (MEMS) silicon resonant cantilever which can only detect the aerosol mass concentration [20]. The cantilevers were fabricated by using silicon bulk MEMS processes. Some new chargers fabricated by using nanomaterials have emerged as well. Hwang et al. designed a $\mathrm{ZnO}$ nanowire charger [23] for aerosol particle charging.

In this study, we developed a micro aerosol sensor, which can detect monodisperse aerosol particle number concentrations in the range of 300-2.5 $\times 10^{4} / \mathrm{cm}^{3}$ and particle sizes in the range of 50-253 $\mathrm{nm}$ based on the diffusion charging principle. The aerosol sensor consists of three essential sections, the charging, precipitation and measurement sections. The three sections are integrated into one chip, composed of a couple of planar electrodes printed on two parallel-assembled circuit boards rather than elaborate structures, such as ion traps and Faraday cages, so as to make the sensor simple and amenable to miniaturization.

\section{Theory of Operation}

The aerosol sensor is based on the fact that the average charge $\bar{q}$ per particle and the particle size $d_{p}$ have a certain exponential relationship [24] which can be expressed as follows:

$$
\bar{q}\left(d_{p}\right)=c \cdot d_{p}^{x}
$$

where $\mathrm{c}$ is a constant determined through sensor calibration, $x$ is a coefficient determined by the value of $N_{i} \cdot t_{r}$ (Fuchs theory). $N_{i}$ is the number concentration of ions in the charging section, $t_{r}$ is the exposure time of particles exposed to ions in the charging section. In general, the coefficient $x$ is close to 1 , which indicates a substantially linear relationship between the average charge and the particle size [1,25].

A schematic overview of the aerosol sensor is given in Figure 1. The aerosol sensor consists of three sections: charging section, precipitation section and measurement section, in each of which a pair of parallel electrodes are located and distributed along the flow channel. Firstly the aerosol particles 
and gas ion are electrically charged via diffusion charging in the charging section, where the charges are generated by a corona discharger with a tungsten needle-tip electrode loaded with a sufficiently high voltage (named corona discharge voltage) to ionize the surrounding air. Then the charged aerosol particles enter into the precipitation section, where a square signal with low and high voltages of $V_{1}$ and $V_{2}$ is imposed onto two opposite planar electrodes with a frequency of $0.1 \mathrm{~Hz}$. At the $V_{1}$ stage all gas ions are deposited on the planar electrodes in the precipitation section, and all charged aerosol particles pass through the precipitation section, deposit on the planar electrodes in the measurement section and export a total electrical current $I_{1}$. At the $V_{2}$ stage all gas ions and a part of the charged aerosol particles are deposited in the precipitation section, and the rest of the charged aerosol particles pass through the precipitation section, arrive at the measurement section and produce a total electrical current $I_{2}$. The number concentration and the particle size can be figured out from the measurement currents $I_{1}$ and $I_{2}$ as follows [16]:

$$
\begin{gathered}
N=S_{N} \cdot\left(I_{1}-I_{2}\right) \\
d_{p}=S_{d} \cdot \frac{I_{1}}{I_{1}-I_{2}}
\end{gathered}
$$

where $N$ refers to the number concentration, $d_{p}$ refers to the particle size, $I_{1}$ and $I_{2}$ are the sensor output currents that correspond with the precipitating voltages $V_{1}$ and $V_{2}$, respectively. $S_{N}$ and $S_{d}$ are the constants dependent on the sensor geometry and working conditions.

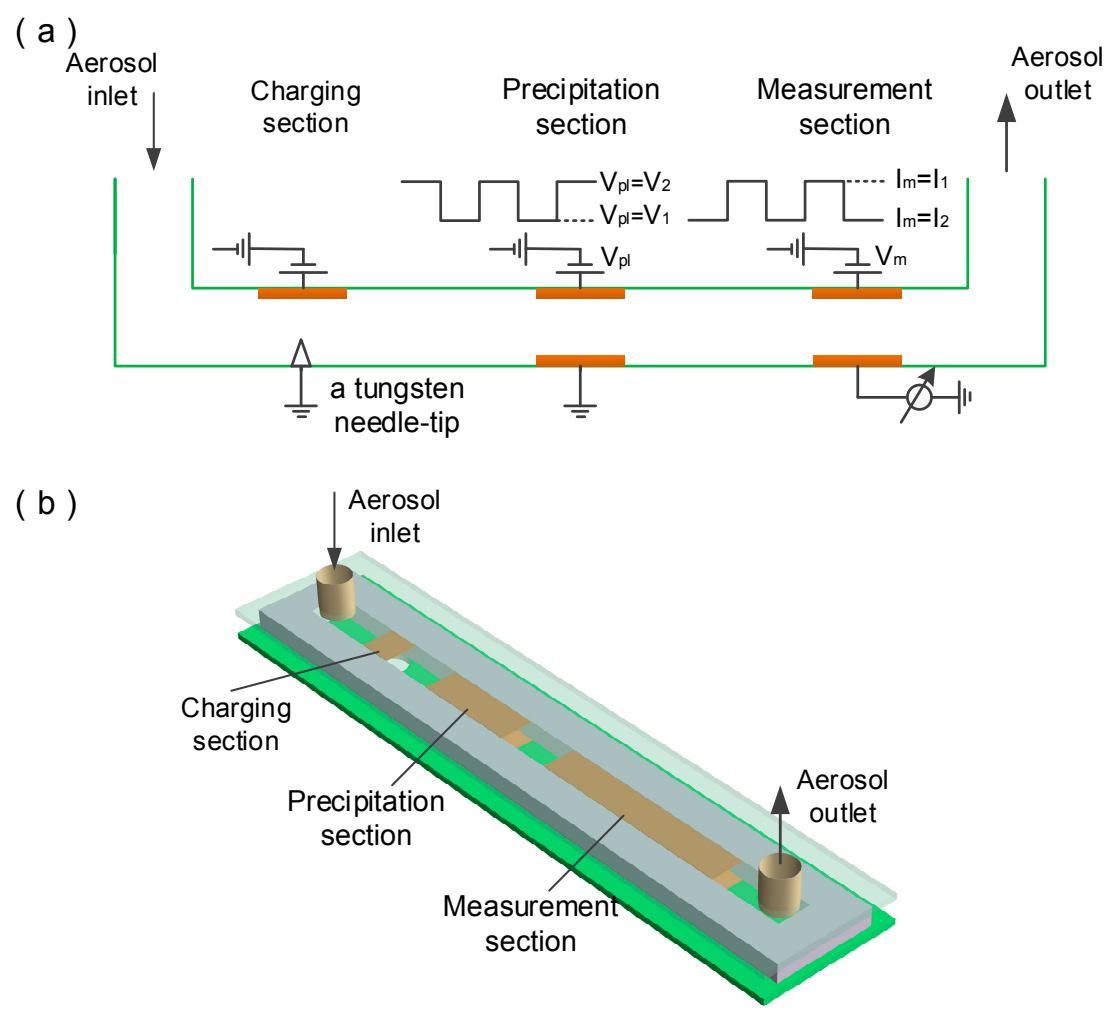

Figure 1. (a) The principle structure of the proposed aerosol sensor; and (b) Three-dimensional structure model diagram of the proposed aerosol sensor.

\section{Experimental Setup}

Figure 2 shows the schematic diagram of the experimental setup for testing the developed aerosol sensor assessed with monodisperse airborne ultrafine particles. The experimental system involves an aerosol generator (ATM-220, TOPAS, Frankfurt, Germany), diffusion dryer (DDU-570, TOPAS), DMA (Model 3085, TSI, St. Paul, MN, USA), neutralizer (Model 3087, TSI), CPC (Model 3772, TSI), electrometer (Model 6430, Keithley, Cleveland, OH, USA) and the developed aerosol 
sensor. Polydisperse sodium chloride $(\mathrm{NaCl})$ aerosol particles were generated by the aerosol generator, then the diffusion dryer absorbed excess water in the polydisperse aerosol. The DMA was used to select mono-sized aerosol particles according to their electrical mobility, and the charges existing in the aerosol particles were neutralized by the neutralizer to ensure all charged particles had been neutralized before entering into the aerosol sensor. The subsequent CPC accurately counted the number concentration. The selected monodisperse aerosol particles successively entered into the charging, precipitation and measurement sections of the aerosol sensor. The measurement currents were detected in real time by using the Keithley 6430 electrometer which has a peak-to-peak noise of $0.4 \mathrm{fA}$. The output frequency of the sensor was $0.1 \mathrm{~Hz}$. The flow rate of the aerosol flow was set as $0.4 \mathrm{LPM}$.

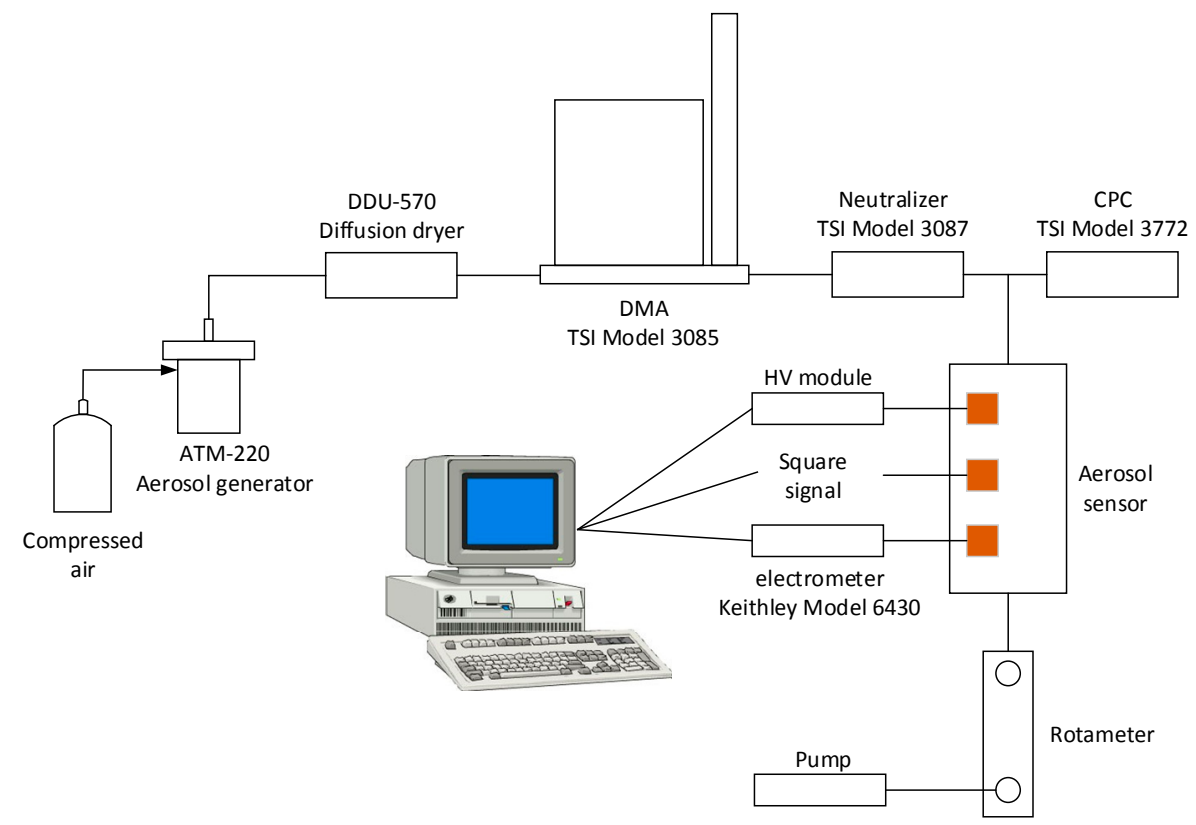

Figure 2. Schematic diagram of the experimental setup for testing the aerosol sensor.

\section{Preliminary Experiments}

In order to determine the number concentration and particle size of monodisperse aerosol particles, a series of preliminary experiments needed to be conducted. The first preliminary experiments were conducted to determine the optimal working conditions for the aerosol sensor. The corona discharge voltage, the square voltages applied on the precipitation electrodes, and the voltage imposed on the measurement electrodes for collecting the charge current were tested and optimized. Firstly the corona discharge voltage of the aerosol sensor was determined by gradually increasing the voltage on the charging section until the corona discharge occurred and self-sustained. Then, the discharge voltage was maintained. The measurement voltage imposed on the measurement electrodes was determined by increasing the magnitude of the measurement voltage until the charge current achieved saturation while the precipitation electrodes were floating, which ensured all charged aerosol particles to be detected could be collected by the measurement section. The square voltages applied on the precipitation electrodes was determined by the criteria that the low voltage was used for depositing the excess gas ions except the charged aerosol particles onto the precipitation section and the high voltage was for depositing a part of the charged aerosol particles onto the precipitation section. For our developed sensor, the corona voltage was finally set as $1400 \mathrm{~V}$, the low and high voltages of the precipitation square signal were set as $0.9 \mathrm{~V}$ and $3 \mathrm{~V}$, respectively, while the voltage imposed on the measurement electrodes was $-5 \mathrm{~V}$. 
The second experiments were conducted to determine the initial parameters for the aerosol sensor. Two conditions with and without diffusion charging were tested, respectively. In the experiments, pure air without an aerosol was used as the gas medium and the precipitation section was switched off. The experimental results are shown in Table 1, where the currents were collected at the measurement section when the charging section was turned off and on, respectively. The initial parameters were used to test the initial condition of the sensor, for example the average current under air without charging indicates the leakage current of the sensor.

Table 1. The initial parameters for the aerosol sensor.

\begin{tabular}{ccc}
\hline Conditions & Average Current (fA) & Standard Deviation (fA) \\
\hline Air without charging & -41.4 & -1.4 \\
Air with diffusion charging & -83.7 & -7.6 \\
\hline
\end{tabular}

\section{Results and Discussion}

Monodisperse $\mathrm{NaCl}$ aerosol particles with particle sizes in the range of 50-253 $\mathrm{nm}$ and number concentrations in the range of 300-2.5 $\times 10^{4} / \mathrm{cm}^{3}$ were measured by using the developed aerosol sensor. Figure 3 shows the results of the tested current $I_{1}$ as a function of the particles' value of $N \cdot d_{p}$. Figure 3 indicates a linear relationship between $I_{1}$ and $N \cdot d_{p}$ with a correlation coefficient of $R^{2}=0.9579$. The results are in good agreement with a previous report [17].

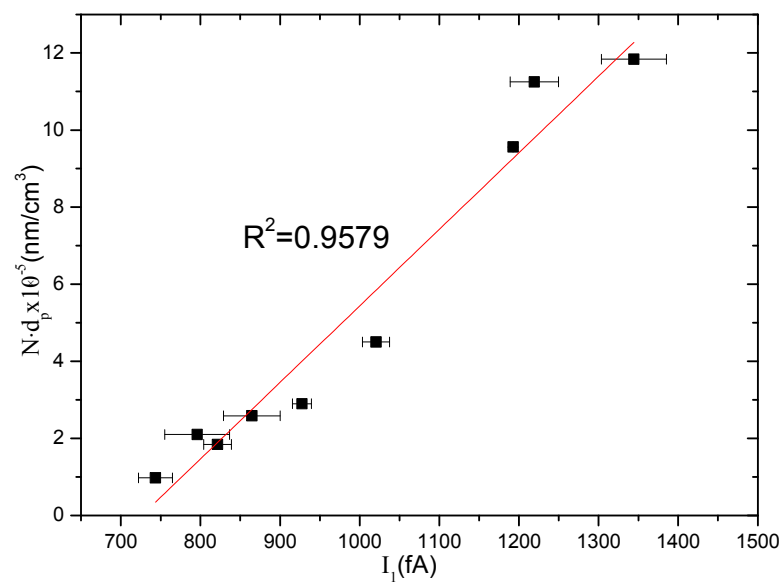

Figure 3. The relationship between $N \cdot d_{p}$ and $I_{1}$ for the measurement of monodisperse aerosols with particle sizes in the range of 50-253 nm and number concentrations in the range of 300-2.5 $\times 10^{4} / \mathrm{cm}^{3}$.

Figures 4 and 5 show the relationship between the particle number concentration $N$ and the measured $I_{1}-I_{2}$, and the relationship between the aerosol particle size $d_{p}$ and the measured $I_{1} /\left(I_{1}-I_{2}\right)$, respectively. The results indicate that the size domain displayed a turning point at $d_{p}=150 \mathrm{~nm}$. The number concentration $N$ exhibited different linear relationships with the measured $I_{1}-I_{2}$ in two regions of $50<d_{p}<150 \mathrm{~nm}$ and $150<d_{p}<253 \mathrm{~nm}$, respectively. The relationship between the particle size $d_{p}$ and the measured $I_{1} /\left(I_{1}-I_{2}\right)$ was similar. Linear fits were conducted for the results and the relationships could be expressed as follows:

For $50<d_{p}<150 \mathrm{~nm}$ :

$$
\begin{aligned}
& N=229.49 \cdot\left(I_{1}-I_{2}\right)-118484 \\
& d_{p}=150.81 \cdot \frac{I_{1}}{I_{1}-I_{2}}-259.31
\end{aligned}
$$

For $150<d_{p}<253 \mathrm{~nm}$ :

$$
N=7.4064 \cdot\left(I_{1}-I_{2}\right)-2300
$$




$$
d_{p}=246.2 \cdot \frac{I_{1}}{I_{1}-I_{2}}-247.63
$$

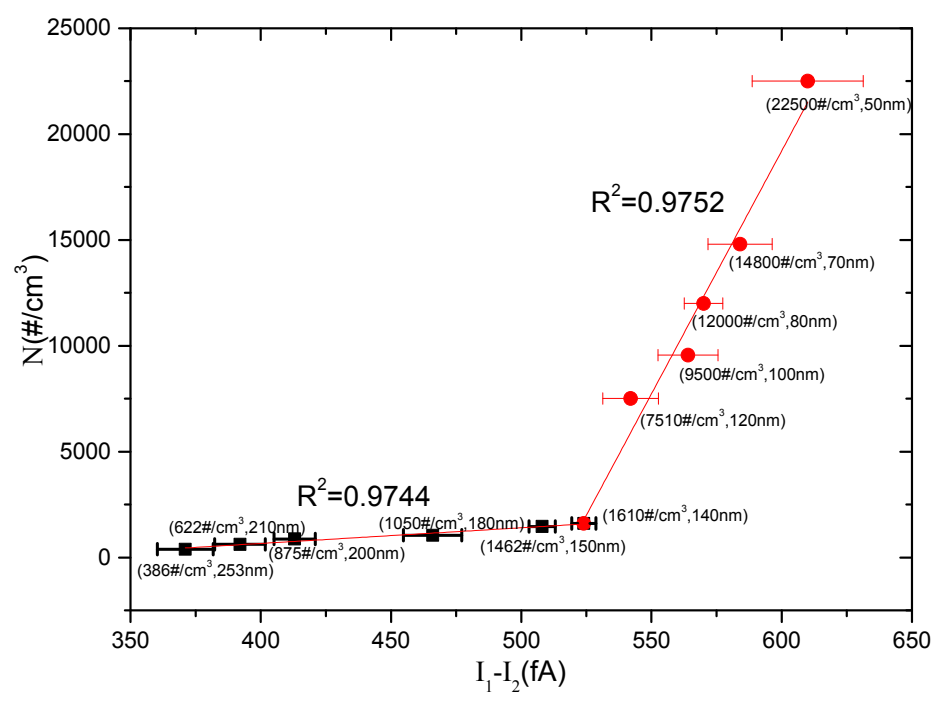

Figure 4. The relationship between $N$ and $I_{1}-I_{2}$ for testing monodisperse aerosols with diameters in the range of $50-253 \mathrm{~nm}$.

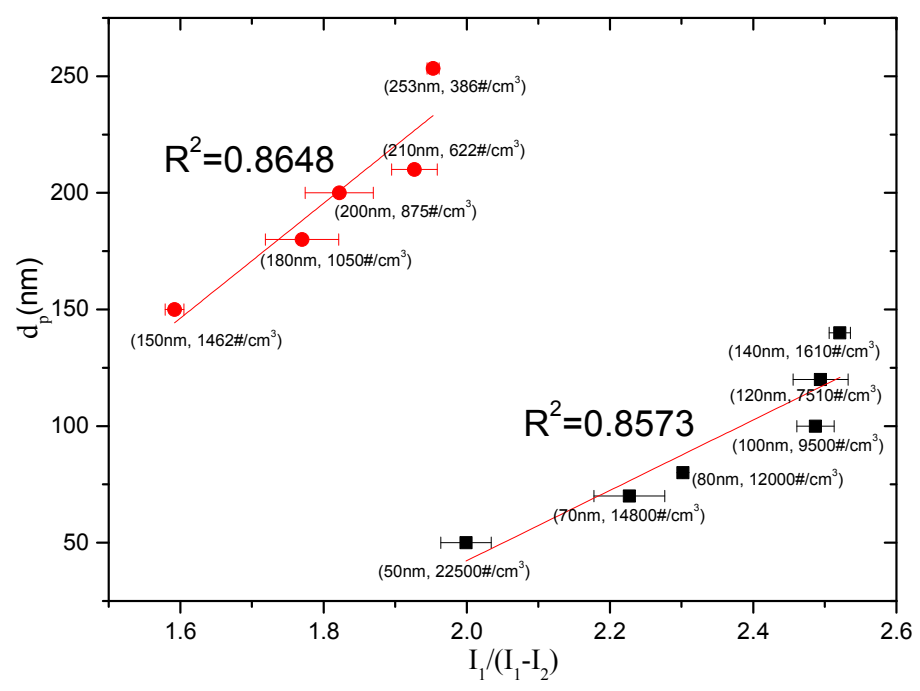

Figure 5. The relationship between $d_{p}$ and $I_{1} /\left(I_{1}-I_{2}\right)$ for testing monodisperse aerosols with number concentrations in the range of $300-2.5 \times 10^{4} / \mathrm{cm}^{3}$.

The change at the turning point of $d_{p}=150 \mathrm{~nm}$ might be attributed to the variation of the particle flow behavior. The Knudsen number $K_{n}=2 \bar{\lambda} / d_{p}$, referring to the ratio of the gas' molecular mean free path to the particle dimension, determines the type of particle flow. At normal temperature and pressure (NTP), the gas molecular mean free path is $\bar{\lambda}=66.4 \mathrm{~nm}$ [1]. It is presumed that at $d_{p}<150 \mathrm{~nm}$ the aerosol particle flow presents a slip flow regime, but a continuum regime flow at $d_{p}>150 \mathrm{~nm}$. The transformation of the flow behavior affects the particle diffusion charging and thus changes the relationships between the measurement currents and the particle parameters [19].

Based on the abovementioned analysis, the aerosol sensor figures out the measured aerosol number concentration from the relationship between $N$ and $I_{1}-I_{2}$ shown in Figure 4, and then derives the measured particle size from the relationship between $N \cdot d_{p}$ and $I_{1}$ shown in Figure 3. The comparison between the measured results by the aerosol sensor and the reference data are shown in 
Figure 6, where the reference data of the number concentration and the particle size were detected by $\mathrm{CPC}$ and DMA, respectively.

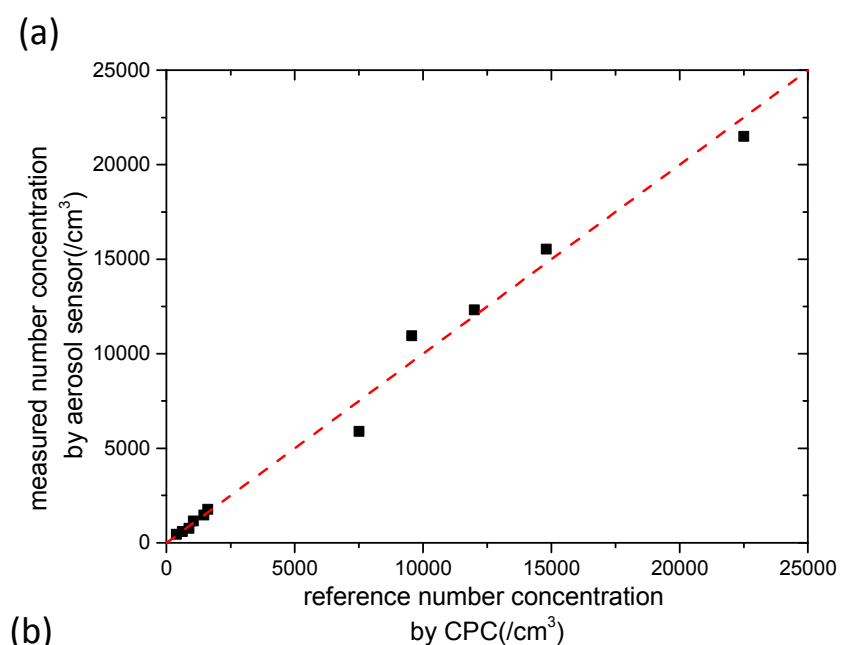

(b)

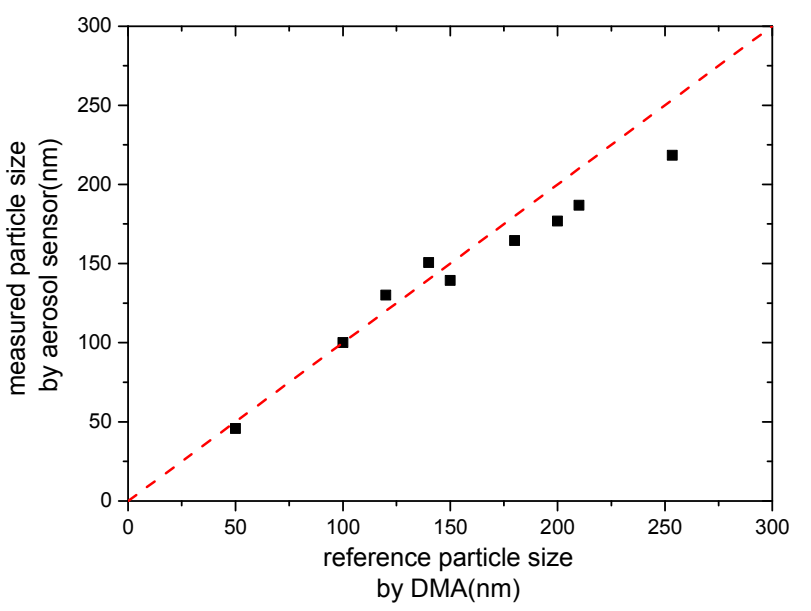

Figure 6. (a) Comparison of results measured by the aerosol sensor and reference data determined by CPC for number concentration; and (b) comparison of results measured by the aerosol sensor and reference data determined by DMA for particle size.

Table 2 lists the mean square deviations of the sensor results from the reference data for the number concentration and particle size, which were $6.7 \%$ and $3.8 \%$, respectively. The experimental results proved the effectiveness of the aerosol sensor for detecting the number concentration and the particle size of monodisperse ultrafine aerosols. Actually the developed aerosol sensor can detect not only monodisperse aerosol particles but also polydisperse aerosol particles with normal distribution based on the same diffusion charging theory. The detected particle size is the number-averaged particle diameter of the polydisperse aerosol. For measuring polydisperse aerosol particles, a calibration experiment using standard polydisperse particles with a normal distribution is required prior to the particle detection. Compared with existing instruments [26,27] using different particle types (e.g., $\mathrm{NaCl}, \mathrm{PSL}, \mathrm{DOP}$ ) and other on-field micro-aerosol sensors, some features of the performance of the sensor still needs to be improved on, such as measurement accuracy, miniaturization, and applications with polydisperse particles. 
Table 2. The deviations of the measured results by aerosol sensor from reference data.

\begin{tabular}{cccc}
\hline Parameter & Mean Square Deviation & Maximum Deviation & Minimum Deviation \\
\hline Number concentration & $6.7 \%$ & $21 \%$ & $0.03 \%$ \\
Aerosol particle size & $3.8 \%$ & $13.8 \%$ & $0.1 \%$ \\
\hline
\end{tabular}

\section{Conclusions}

This paper has presented a micro-aerosol sensor based on diffusion charging and electrical detection to measure number concentrations of 300-2.5 $\times 10^{4} / \mathrm{cm}^{3}$ and particle sizes of 50-253 nm. The aerosol sensor is composed of planar electrodes printed on two circuit boards assembled in parallel, which integrate charging, precipitating and measurement elements into one chip. The device is simple and practical for handheld instruments. The comparison between the results of the proposed aerosol sensor and the reference data of the measured number concentration and particle size of monodisperse aerosol presented a satisfactory result and proved the effectiveness of the aerosol sensor for detecting ultrafine aerosol particles. In the future, we will further improve the performances of the sensor on such as measurement accuracy, miniaturization, and applications to polydisperse particles.

Acknowledgments: This work was supported by the National Key Project of Scientific Instrument and Equipment Development (2012YQ030261).

Author Contributions: Chao Zhang developed the system, conducted the experiments, and wrote the article under the supervision of Rong Zhu. Wenming Yang designed the aerosol sensor. Rong Zhu proposed the original idea.

Conflicts of Interest: The authors declare no conflict of interest.

\section{References}

1. John, W. Size Distribution Characteristics of Aerosols. In Aerosol Measurement, Principles, Techniques and Applications, 4th ed.; Pramod, K., Paul, A.B., Klaus, W., Eds.; Wiley: Hoboken, NJ, USA, 2011; pp. 41-54.

2. William, C.H. Aerosol Technology, Properties, Behavior and Measurement of Airborne Particles, 2nd ed.; John Wiley \& Sons, Inc.: Hoboken, NJ, USA, 1998.

3. Maynard, A.D.; Kuempl, E.M. Airborne nanostructured particles and occupational health. J. Nanopart. Res. 2005, 7, 587-614. [CrossRef]

4. Bakand, S.; Hayes, A.; Dechsakulthorn, F. Nanoparticles: A review of particle toxicology following inhalation exposure. Inhalation Toxic. 2012, 24, 125-135. [CrossRef] [PubMed]

5. Oberdörster, G. Significance of particle parameters in the evaluation of exposure-dose response relationships of inhaled particles. Part. Sci. Technol. 1996, 14, 135-151. [CrossRef]

6. Oberdörster, G.; Celein, R.M.; Ferin, J.; Weiss, B. Association of particulate air pollution and acute mortality: Involvement of ultrafine particles. Inhalation Toxic. 1995, 7, 111-124. [CrossRef] [PubMed]

7. Kreyling, W.G.; Semmler, M.; Erbe, F.; Mayer, P.; Takenaka, S.; Schulz, H.; Oberdörster, G.; Ziesenis, A. Translocation of ultrafine insoluble iridium particles from lung epithelium to extrapulmonary organs is size dependent but very low. J. Toxicol. Environ. Health Part A 2002, 65, 1513-1530. [CrossRef] [PubMed]

8. Oberdörster, G.; Oberdörster, E.; Oberdörster, J. Nanotoxicology: An emerging discipline evolving from studies of ultrafine particles. Environ. Health Perspect. 2005, 113, 823-839. [CrossRef] [PubMed]

9. ICRP, International Commission on Radiological Protection. ICRP Publication 66: Human Respiratory Tract Model for Radiological Protection; Elsevier Health Sciences: London, UK, 1994; pp. 1-482.

10. Koo, J.H.; Hirleman, E.D. Review of Principles of Particle Size Measurements. In Recent Advances in Spray Combustion: Spray Atomization and Drop Burning Phenomena, 1st ed.; Kuo, K.K., Ed.; American Institute of Aeronautics and Astronautics: Reston, VA, USA, 1996; Volume 1, pp. 3-32.

11. Black, D.L.; McQuay, M.Q.; Bonin, M.P. Laser-based techniques for particle-size measurement: A review of sizing methods and their industrial applications. Progr. Energy Combust Sci. 1996, 22, 267-306. [CrossRef]

12. Wang, S.C.; Flagan, R.C. Scanning electrical mobility spectrometer. Aerosol Sci. Technol. 1990, 13, $230-240$. [CrossRef] 
13. Mamakos, A.; Ntziachristos, L.; Samaras, Z. Diffusion broadening of DMA transfer functions, Numerical validation of Stolzenburg model. J. Aerosol Sci. 2007, 38, 747-763. [CrossRef]

14. McMurry, P.H. The history of condensation nucleus counters. Aerosol Sci. Technol. 2000, 33, $297-322$. [CrossRef]

15. Marra, J.; Den, B.W.; Goossens, H.; Kessels, S. Nanoparticle monitoring for exposure assessment. IEEE Nanotechnol. Mag. 2009, 3, 6-37. [CrossRef]

16. Marra, J.; Voetz, M.; Kiesling, H.J. Monitor for detecting and assessing exposure to airborne nanoparticles. J. Nanopart. Res. 2010, 12, 21-37. [CrossRef]

17. Fierz, M.; Houle, C.; Steigmeier, P.; Burtscher, H. Design, calibration, and field performance of a miniature diffusion size classifier. Aerosol Sci. Tech. 2011, 45, 1-10. [CrossRef]

18. Fierz, M.; Burtscher, H.; Steigmeier, P.; Kasper, M. Field measurement of particle size and number concentration with the Diffusion Size Classifier (DiSC). SAE Int. 2008. [CrossRef]

19. Bau, S.; Zimmermann, B.; Payet, R.; Witschger, O. A laboratory study of the performance of the handheld diffusion size classifier (DiSCmini) for various aerosols in the $15-400 \mathrm{~nm}$ range. Environ. Sci. Process. Impacts 2015, 17, 261-269. [CrossRef] [PubMed]

20. Wasisto, H.S.; Merzsch, S.; Uhde, E.; Waag, A.; Peiner, E. Handheld personal airborne nanoparticle detector based on microelectromechanical silicon resonant cantilever. Microelectron. Eng. 2015, 145, 96-103. [CrossRef]

21. Liang, D.; Shih, W.P.; Chen, C.S.; Dai, C.A. A miniature system for separating aerosol particles and measuring mass concentrations. Sensors 2010, 10, 3641-3654. [CrossRef] [PubMed]

22. Morris, D.R.; Fatisson, J.; Olsson, A.L.; Tufenkji, N.; Ferro, A.R. Real-time monitoring of airborne cat allergen using a QCM-based immunosensor. Sens. Actuators B: Chem. 2014, 190, 851-857. [CrossRef]

23. Park, C.W.; Lee, S.G.; Kim, M.O.; Kim, J.; Hwang, J. Development and performance test of a ZnO nanowire charger for measurements of nano-aerosol particles. Sens. Actuators A: Phys. 2015, 222, 1-7. [CrossRef]

24. Jung, H.; Kittelson, D.B. Characterization of aerosol surface instruments in transition regime. Aerosol Sci. Technol. 2005, 39, 902-911. [CrossRef]

25. Adachi, M.; Kousaka, Y.; Okuyama, K. Unipolar and bipolar diffusion charging of ultrafine aerosol particles. J. Aerosol Sci. 1985, 16, 109-123. [CrossRef]

26. Price, H.D.; Stahlmecke, B.; Arthur, R.; Kaminski, H.; Lindermann, J.; Däuber, E.; Asbach, C.; Kuhlbusch, T.A.; Berube, K.A.; Jones, T.P. Comparison of instruments for particle number size distribution measurements in air quality monitoring. J. Aerosol Sci. 2014, 76, 48-55. [CrossRef]

27. Zimmerman, N.; Pollitt, K.J.G.; Jeong, C.H.; Wang, J.M.; Jung, T.; Cooper, J.M.; Wallace, J.S.; Evans, G.J. Comparison of three nanoparticle sizing instruments: The influence of particle morphology. Atmos. Environ. 2014, 86, 140-147. [CrossRef]

(C) 2016 by the authors; licensee MDPI, Basel, Switzerland. This article is an open access article distributed under the terms and conditions of the Creative Commons by Attribution (CC-BY) license (http://creativecommons.org/licenses/by/4.0/). 